\title{
TUBERCULOUS OSTEOMYELITIS OF MANDIBLE: A RARE CASE REPORT
}

Ravish Mishra ${ }^{1}$, B. B. Mall ${ }^{1}$, Laxmi Kandel ${ }^{2}$, Santosh Kandel ${ }^{2}$

\section{ABSTRACT}

Tuberculous osteomyelitis of mandible is an extremely rare condition, particularly in comparison to pyogenic infections and neoplastic diseases involving the mandible. Hereby we are reporting such type of case in a ten year old male, presented with draining sinus over right mandible since 3 months proved later as tuberculous osteomyelitis in absence of a primary focus and responded well to antitubercular treatment.

KEY WORDS: Osteomyelitis mandible,tuberculous osteomyelitis

1. Lecturer, Department of Oral and Maxillofacial Surgery, UCMS College of Dental Surgery, Bhairahawa, Nepal

2. Residents, Department of Oral and Maxillofacial Surgery, UCMS College of Dental Surgery, Bhairahawa, Nepal.

\section{Corresponding Author:}

Dr. Ravish Mishra

Assistant Professor

Department of Oral and Maxillofacial Surgery

UCMS College of Dental Surgery

Bhairahawa, Nepal 


\section{INTRODUCTION}

Tuberculosis (TB) has become a rare disease in the developed countries, but it remains a serious Problem in developing countries. A report says that every year, about 20 million prevalent cases and 8 million new cases are reported. WHO has documented that approximately 3 million people die annually of TB and this is more common in developing countries ${ }^{1}$. TB presents itself in two forms, primary and secondary. Primary occurs through direct infection and secondary through lymph nodes. Tuberculous osteomyelitis is very rare entity occurring more often in young individuals and usually in the late stage of disease.

The sites most commonly involved are dorsal and lumbar vertebrae and epiphysis and diaphysis of long bones. Flat bones, including those of skull and mandible are rarely affected. Incidence of tuberculous osteomyelitis of jaw bone is very low ${ }^{2,3,4,6}$. Due to rarity of tuberculous osteomyelitis of mandible, it seldom arouses clinical suspicion especially when a positive history of a systemic infection or therapy is denied. We report a case of a ten year old male, presented with draining sinus over right mandible since 3 months, proved later as tuberculous osteomyelitis in absence of a primary focus and responded well to antitubercular treatment.

\section{CASE REPORT}

A 10-year-old male reported to the Department of Oral and Maxillofacial Surgery, UCMS College of Dental Surgery, Bhairahawa, Nepal with swelling and painalong with draining sinus over the right submandibular region of face (Figure 1). On history taking, it was revealed that the swelling was present for past 3 months which was of spontaneous origin. The patient was prescribed multiple courses of antibiotics by outside general practitioners, but there was no significant improvement. There was no past history of trauma, antitubercular treatment and family history of tuberculosis. The patient was average built, moderately nourished and afebrile at the time of examination. The patient gave a history of generalized weakness and pain associated with the swelling since 3 months.

General physical and systemic examinations did not reveal any significant diagnostic information. Local examination reveals a swelling over the right submandibular region of approximately $3.5 \times 3.5 \mathrm{~cm}$ size with increase in size with time. Overlying skin was normal in colour but swelling was tender on palpation with a discharging sinus. On pressure, thick yellow pus with blood was noticed. Margins of the sinus were hyperemic. There was no significant peripheral lymphadenopathy. Intraoral examination was normal. Provisional diagnosis of space infection / periapical abscesswas made while differential diagnosis included tuberculous osteomyelitis of mandible or any malignant bone tumor.

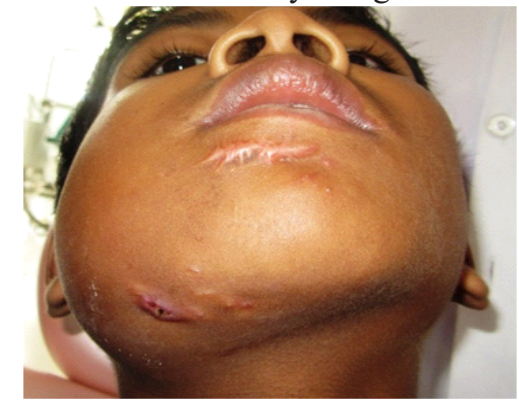

Figure 1 Extraoral photograph showing right unilateral diffuse swelling over right body of the mandible with a sinus. The patient was advised for PA view mandible which revealed well defined, radiolucent, osteolytic lesion surrounding the right lower body of the mandible.

His chest radiograph did not reveal any evidence of tuberculosis. Routine hematological finding included WBC counts of 9600 cells $/ \mathrm{mm} 3$ and $\mathrm{Hb}$ of $11.4 \mathrm{gm} / \mathrm{dl}$. Erythrocyte sedimentary rate was $60 \mathrm{~mm}$ at the end of 1 hour and Mantoux test was negative, serum HIV and HBsAg were negative. Computed tomography (CT) scan showed irregularity of right lower body of the mandible with lytic areas and sclerosis with erosions at some place (Figure 2). Surgical exploration was done for excisional biopsy and specimen was sent for histopathological examination. Histopathological examination showed predominantly granulation tissue with scattered Langhans type giant cells, many mononuclear cells, few epitheloid cells forming ill defined granuloma at places with fibrous area, reactive bone trabeculae and areas of haemorrhages, suggestive of a granulomatous lesion, probably tuberculosis (Figure 3).

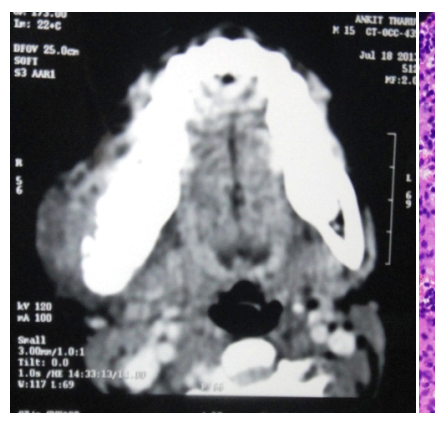

Figure 2

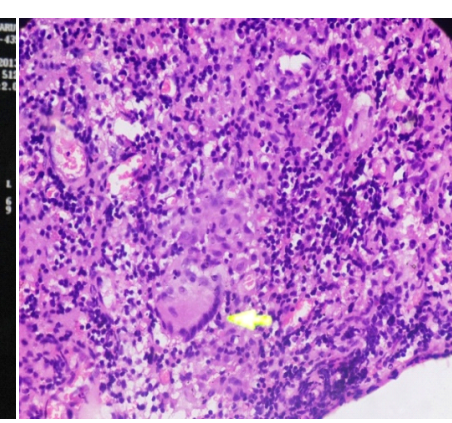

Figure 3
Figure 2 Plain CT scan showing an osteolytic lesions in the body of the mandible on right side.Figure 3histopathological report (40 x magnification) showing granuloma comprising of epitheloid cells, lymphocytes and Langhans giant cells (arrow). 
Based on the clinical, radiographic and histopathological examination a final diagnosis of tuberculous osteomyelitis of mandible was made and the patient was given anti tubercular treatment (ATT): 2HRZE/4HR as per RNTCP-DOTS regimen Cat $\mathrm{I}$. The patient responded well to the treatment with complete remission and there was no evidence of recurrence and surgical corrective steps were taken (Figure 4)

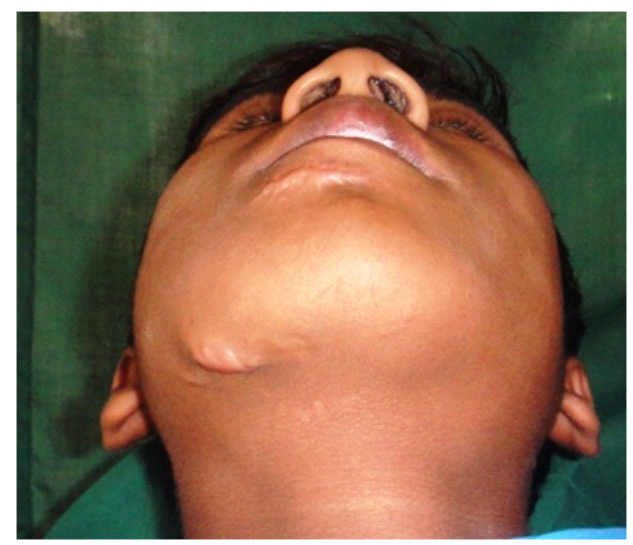

Figure 4 Extraoral photograph showing the residual scar on right side of submandibular region after complete resolution of the swelling

\section{DISCUSSION}

TB is a chronic granulomatous disease that can affect various systems of the body. In human Mycobacterium tuberculosis, Mycobacterium bovis and atypical mycobacterium causes the disease $^{7}$. After a decrease of TB in developed countries up to the mid 1980s, the incidence of TB has been increasing steadily in many countries during the last two decades ${ }^{8}$. Involvement of bone occurs in 1 to $3 \%$ of patients with extra pulmonary tuberculosis and spine represents $50 \%$ of these lesions ${ }^{9,}{ }^{10}$.Tuberculosis of mandible is considered a rare disease which apparently affects both sexes, with male preponderance. According to Chapotel ${ }^{5}$ more than $60 \%$ of mandible bone tuberculosis was seen in patients less than 15 years of age but it can present in old age as well. The involvement of the mandible by tuberculous infection is extremely rare as it contains less cancellous bone ${ }^{11}$. The mandibular involvement is more frequent than maxilla ${ }^{12}$ and the alveolar and angle regions have greater affinity. The infection may extend to mandible by:

1. Direct transfer from infected sputum ${ }^{5}$ or infected raw milk of cow $^{13}$ either through an open pulp or an extraction wound or gingival margin or perforation of an erupting tooth.
2. Regional extension of soft tissue lesion to involve the underlying bone ${ }^{5}$.

3. Haematogenous route r, 14,15. $^{12}$.

Predisposing factors for primary tuberculosis of jaw bone include poor oro-dental hygine, dental extractions, periodontitis and leukoplakia $^{15}$.

TB of jaw causes slow necrosis of the bone and may involve the entire mandible. The destruction of the bone in radiographs appears as blurring of trabecular details with irregular of radiolucency. There is erosion of cortex with little tendency to repair. Gradually the bone is replaced by soft trabecular granulation tissue. Caseation appears at places followed by softening and liquefaction. A soft periosteal abscess then forms presenting as a painless soft swelling. This cold abscess later on may burst either intraorally or extraorally forming single or multiple sinuses. This may result in pathological fracture of mandible and sequestration ${ }^{15}$.

TB of mandible presents as multifocal lesion elsewhere in body, involving other bones and lungs. Out of 64 cases reported up to 1939 , about $43 \%$ of the patients with tuberculosis of the mandible had tubercular lesion in the bones elsewhere in the body ${ }^{5,16}$. Chaudhary et al reported a case of tuberculosis of mandible in 4 year old child who failed to respond to antibiotics and tuberculosis was diagnosed subsequently ${ }^{1}$. Mishra et al reported a primary TB of mandible who recovered after 2 years of anti tubercular treatment $(\mathrm{ATT})^{17}$.

The diagnosis of a case of tuberculous osteomyelitis of mandible is extremely difficult ${ }^{18}$ as there are no specific signs pathognomic of infection ${ }^{19}$. The only manifestation may be a localized swelling of the jaw which may be misdiagnosed as a pyogenic abscess or if sinuses are present, may be confused with other granulomatous diseases like actinomycosis. Finally the diagnosis must be established by histological examination of tissue and demonstration of the organisms in the lesions ${ }^{15}$ and prompt treatment with ATT should be started as early as possible.

\section{CONCLUSION}

Despite of its rare occurrence, tuberculous osteomyelitis should be considered as a differential diagnosis when routine therapy fails to bring about improvement in the lesions. Early detection of disease is completely curable and can lead to reversal of all destructive bony changes. 


\section{REFERENCES}

1. Chaudhary S, Kalra N, Gomber S. Tuberculous osteomyelitis of the mandible: A case report in a 4-year old child. Oral Surg Oral Med Oral Pathol Oral Radiol Endod 2004;97:603-6.

2. Hock- Liew E, Shin-Yu L, Chuang-Hwa Y, Wei-Jen C. Oral tuberculosis. Oral Surg Oral Med Oral Pathol Oral Radiol Endod 1996;81:415-20.

3. Gupta MK, Singh M. Primary tuberculosis of mandible. IndianPediatr 2007;44:53-4.

4. Dinkar AD, Prabhudessai V. Primary tuberculosis osteomyelitis of the mandible: A case report. DentomaxillofacRadiol 2008;37:415-20.

5. Chapotel S. Tuberculosemandibularie. Rev Odent 1930;51:444-

6. Bhatt AP, Jayakrishnan A. Tuberculous osteomyelitis of the mandible: A case report. Int J Paediatr Dent 2001;11:304-8.

7. Prabhu SR, Sengupta SK. Bacterial infections due to mycobacteria Tuberculosis. In: Oral disease in the tropics. Prabhu SR, Wilson DF, Daftary DK, Johnson NW. Oxford : Oxford University Press, pp 195-202

8. Rieder HL. Epidemiology of tuberculosis in Europe. EurRespir J Suppl. 1995; 20: 620-632.

9. Sante LR: Principles of Roentgenologic Interpretation, $11^{\text {th }} \mathrm{ed}$ (1958), pp 109. Ann Arbor MI, Edwards Bros.

10. Evanchick CC, Davis DE, Harrington TM: Tuberculosis of peripheral joints: an often missed diagnosis. Rheumatol 1986 , 13:187-191.
11. Sachs SA, Eisenbud L. Tuberculous osteomyelitis of mandible. Oral surg 1977; 44: 425-426.

12. Thomas KH. Oral Pathology. In: Kimpton H, editor. A textbook of oral pathology. $3^{\text {rd }}$ ed. Philadelphia: WB Saunders Company, 1950: 891-895.

13. Schumuziger P. Primary tuberculosis of buccal mucosa. Rev Mans Suisse Odont 1945; 60: 1087-1088.

14. Ratliff DP. Tuberculosis of the mandible. B Dent H 1973; 135 $122-123$

15. K.B. Gupta, M. Machanda, S.P.S Yadav and A. Mittal. Tubercular osteomyelitis of mandible. Indian J Tuberc 2005;52:147-150

16. Meng CM. Tuberculosis of the mandible. J Bone Joint Surgery $1940 ; 22: 17-27$

17. Mishra YC, Bhoyar SC. Primary tuberculous osteomyelitis of mandible. J Indian Dent Assoc 1986; 58:335-339.

18. Darlington CC, Salman I. Oral Tuberculous Lesions. Am Rev Tuberc 1937; 35: 147-149.

19. Tanchester D, Sarin S. Dental lesions in relation to Pulmonary Tuberculosis. JDent Res 1937; 16: 69-70. 